\title{
INCIDENCE AND ORIGIN OF ANDROGENETIC MALES IN X-RAYED HABROBRACON EGGS ${ }^{1}$
}

\author{
ANNA R. WHITING \\ University of Pennsylvania
}

\section{INTRODUCTION}

The terms androgenesis and merogony are sometimes used interchangeably. The former is defined by Wilson (1925) as "the activation of the egg by the sperm followed by development without the participation of the egg nucleus;" the latter as the "development of an egg fragment devoid of a nucleus fertilized by a normal sperm." This distinction is kept in this paper.

The study was undertaken with two objects in view : first, to determine whether low incidence of androgenetic males or high embryonic mortality is responsible for the low ratio of their occurrence as adults; and second, to work out the cytological mechanism underlying androgenesis in Habrobracon.

The literature dealing with androgenesis is considerable. Much of it is summarized in Wilson (1925), Sharpe (1934) and Darlington (1937). Three papers have been selected for discussion here. Packard (1918) exposed unfertilized Chaetopterus eggs in first meiotic metaphase to radium, and fertilized them with untreated sperm. When exposure was relatively long (35 to 50 minutes) the egg nucleus remained attached to the second polar body, the sperm nucleus divided, and development was androgenetic. Hasimoto (1934) identified some silkworm (Bombyx) males as androgenetic. These had developed from eggs which had been exposed to high temperature at time of oviposition when the eggs were undergoing the maturation divisions. These males were diploid, and by means of appropriate genetic combinations, he was able to demonstrate that they arose from the "union of two sperm nuclei in the egg cytoplasm without fertilization with the egg nucleus." Polyspermy is the rule in Bombyx. The third paper (Astaurow, 1937) describes the production of androgenetic males, likewise in Bombyx. They were produced along with the expected classes either by thermo-activation $\left(40^{\circ} \mathrm{C}\right.$. for one hour) after fertilization, or by irradiation of the egg followed by fertilization with untreated sperm, or by both. At X-ray doses lethal to the egg nucleus, androgenetic males developed only after thermo-activation of the fertilized eggs. Heat treatment is used in this form to break diapause.

\section{Material and Methods}

For X-ray treatments a dual-tube self-rectifying outfit with a simultaneous crossfiring technique was used. The secondary voltage was $182 \mathrm{kv}$. and the tube cur-

1 This investigation was completed with the aid of a research grant from the National Cancer Institute of the National Institute of Health, U. S. Public Health Service. The author is also grateful to the University of Pennsylvania and to the Marine Biological Laboratory, Woods Hole, Massachusetts, for use of laboratory facilities, and to Mr. L. R. Hyde for administering the X-ray treatments. The drawings were made by Mrs. Jean Wilson. 
rent on each tube was $25 \mathrm{ma}$. The heavy glass of the tube walls and $5 \mathrm{~mm}$. of bakelite of the tube shields gave the filtering value of $0.2 \mathrm{~mm}$. copper shield. The output intensity was $7210 \mathrm{r}$ per minute, distance $9.5 \mathrm{~cm}$. All breeding was carried on at $30^{\circ} \mathrm{C}$.

Well-fed wild type females of the parasitic wasp Habrobracon juglandis were $\mathrm{X}$-rayed and mated to untreated males which differed from wild type by one or more recessive traits. Eggs laid by these females during the first six hours after treatment had been X-rayed in late metaphase of the first meiotic division (metaphase I) ; the majority of those laid after this time had been treated in first meiotic prophase (prophase I) (Whiting 1938). Lethal dose $^{2}$ for the former is about $2400 \mathrm{r}$; for the latter, about 54,000 r (Whiting, 1941).

From all control crosses of the type used in this study, only diploid biparental females and haploid gynogenetic males are produced. Therefore, when wild type females are mated to males with traits recessive to wild type, daughters are wild type, heterozygous for the recessive traits, while sons have maternal wild type genes only. If this kind of cross is made after the females have been $\mathrm{X}$-rayed, there appear occasionally males which show all the recessive paternal traits (Whiting, 1946a). These males are normal in appearance, fully fertile and transmit paternal traits only. They are, therefore, androgenetic. Their fertility is proof that they are haploid since diploid males which may arise from certain crosses in Habrobracon are always sterile or nearly so.

Repeated tests have shown that androgenetic males arise from eggs treated in metaphase I, and of 381 such eggs observed, six only, 1.57 per cent, developed into these exceptional males (dose $14,420 \mathrm{r}-28,840 \mathrm{r}$ ). Although lethal dose for the nuclei of these eggs is $2400 \mathrm{r}$, androgenetic males have developed in eggs X-rayed with dose as high as 54,000 r (Whiting 1946b).

Eggs laid during the first six hours after treatment $(14,420 \mathrm{r}-36,050 \mathrm{r})$ were collected at one hour intervals, punctured, and fixed in Kahle's fixative. They were stained with the Feulgen technique and mounted whole in Canada balsam.

\section{OBSERVATIONS}

Speicher (1936) found that the most advanced eggs in Habrobracon egg sacs are in "early anaphase of the first maturation" (the author prefers to call this late metaphase I), and described normal oogenesis following oviposition. After the egg is laid, the maturation spindle passes into telophase I. The second division follows immediately. The four haploid groups of chromosomes (1a, 1b, 2a, 2b) lie in a row roughly perpendicular to the egg surface. During anaphase II, polar nuclei la and $2 \mathrm{a}$ remain stationary, $1 \mathrm{~b}$ moves close to $2 \mathrm{a}$, and $2 \mathrm{~b}$ (functional nucleus) sinks deeper into the egg, a membrane forming as it moves. Nucleus 1a soon disintegrates, $1 \mathrm{~b}$ and $2 \mathrm{a}$ unite and form a metaphase plate which divides and then disintegrates. Cleavage is of the usual insect type, with nuclei moving about until blastoderm formation, when cell membranes first appear.

2 Apparent inconsistencies in lethal doses in successive papers dealing with Habrobracon eggs are due to changes in method of calibration at the Marine Biological Laboratory. Conditions of treatment have not varied. In this paper all doses have been corrected for the latest measurements. 
Plate I
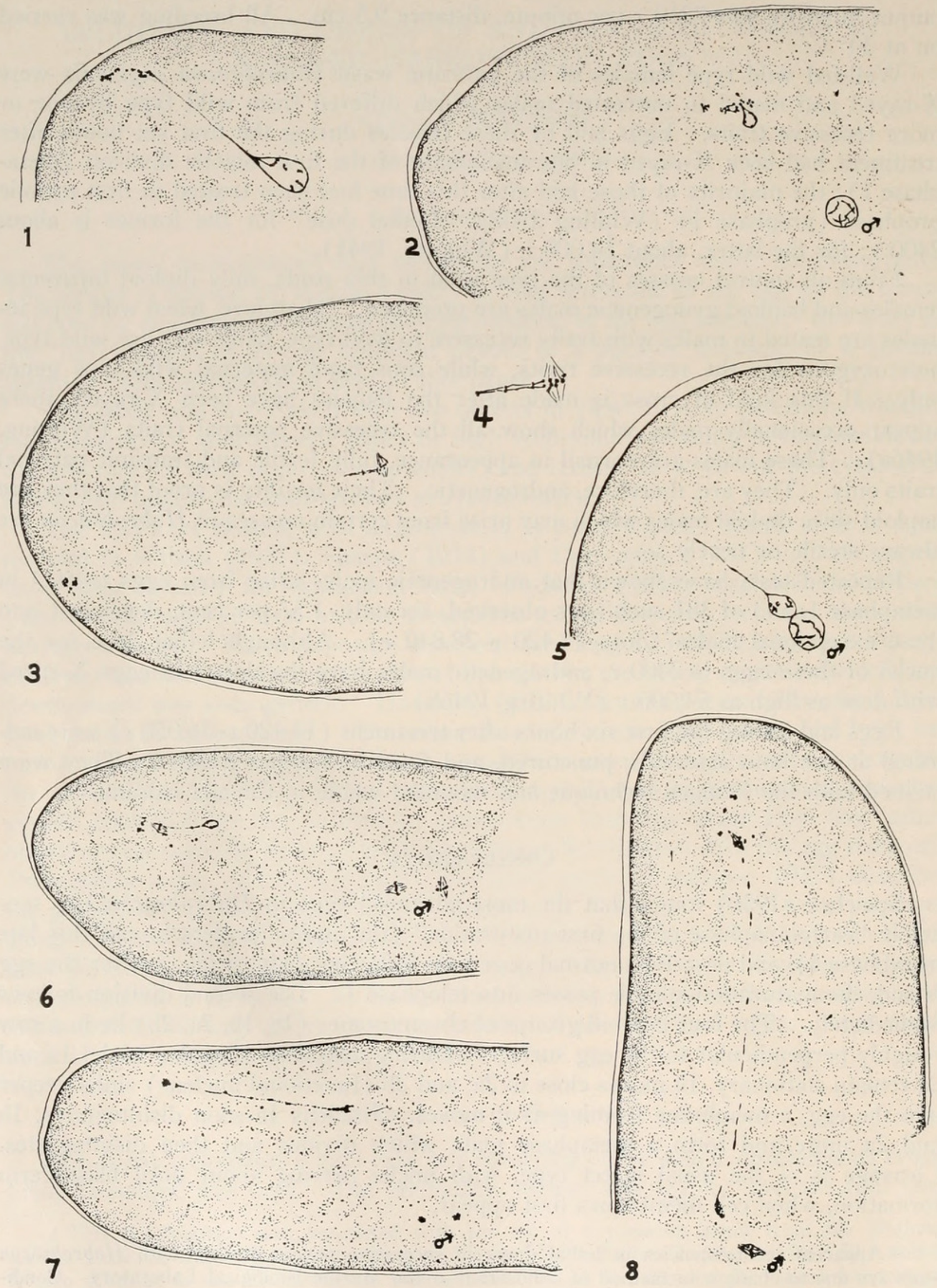
After treatment with X-rays in prophase I, chromatin fragments, bridges, or both may occur in division I, or in division II, or in both divisions (Whiting, 1945a). Bridges occur but rarely in division II and when present appear to be single. After treatment in metaphase I, chromatin fragments (never bridges) may be seen between chromosome groups in telophase I and chromatin bridges appear in division II. These bridges may occur between nuclei $1 \mathrm{a}$ and $2 \mathrm{a}$, or $1 \mathrm{~b}$ and $2 \mathrm{~b}$, or between both pairs, never between $2 \mathrm{a}$ and $1 \mathrm{~b}$. They are made up of several chromatin threads and are present in both regions when dose is high. The attached egg pronucleus can move a long distance without breaking the bridges, and under these conditions it is pulled out into a "tear-drop" (Whiting, 1945b). Controls, of course, do not show fragments or bridges.

These bridges may retard the female pronucleus, but that they do not often stop it completely at relatively low doses is demonstrated by the fact that after lethal dose (2400 r) all but 2.4 per cent of unfertilized eggs develop well beyond first cleavage before death, and that these 2.4 per cent advance to first cleavage before dying (Whiting, 1945a).

These facts suggested to the author that the chromatin bridges formed during the second meiotic division of eggs X-rayed in metaphase I might sometimes retard the attached egg pronucleus to such a degree that the untreated sperm pronucleus would cleave before the egg pronucleus could reach it.

There were 702 eggs prepared and studied. Of these, 58.55 per cent were useless, either because they had been fixed at stages previous to syngamy or cleavage, or were not clearly stained; 41.45 per cent were of significance. They included all eggs undergoing syngamy as well as those in cleavage, where either chromosome number or presence or absence of chromosome aberrations demonstrated which pronuclei had taken part in cleavage. Of the 291 eggs fulfilling these requirements, three (1.03 per cent) only were found in which androgenetic development had begun (Plate 1, Figs. 6, 7 and 8). Three eggs not included in the 291 suggested incipient androgenesis. In each the male pronucleus was preparing for first cleavage while the female pronucleus was greatly retarded (Plate 1, Fig. 2). If these are accepted as androgenetic, a maximum of six among 294, or 2.04 per cent, is obtained. This does not differ significantly from 1.57 per cent of adult survivors, and demonstrates

\section{Plate I}

All illustrations were drawn with aid of a camera lucida from whole mounts of eggs which had been X-rayed in first meiotic metaphase. Fertilization was accomplished by untreated sperm. Anterior end and lateral view of each egg is shown. Cytoplasm is somewhat conventionalized. The lenses employed were a Spencer $2 \mathrm{~mm}$. n. a. 1.3 apochromatic oil immersion objective and $\mathrm{a} \times 5$ or $\times 10$ compensating ocular.

1. Attached pronucleus of unfertilized egg. Dose $28,840 \mathrm{r} . \quad \times 650$.

2. Attached and greatly retarded female pronucleus with normal male pronucleus. Egg $\mathrm{X}$-rayed with $28,840 \mathrm{r}$. $\times 650$.

3. First cleavage spindle of unfertilized egg. Chromatin bridges still attached to some cleavage chromosomes. Dose 14,420 r. $\times 370$.

4. Cleavage spindle of Figure 3 in detail. $\times 650$.

5. Syngamy. Egg X-rayed with 36,050 r. $\times 650$.

6. Second cleavage of androgenetic development. Egg pronucleus greatly retarded. Egg $\mathrm{X}$-rayed with $36,050 \mathrm{r}$. $\times 370$.

7. Second cleavage of androgenetic development. Egg X-rayed with $28,840 \mathrm{r}$. $\times 370$.

8. First cleavage of androgenetic development. Egg X-rayed with $14,420 \mathrm{r} . \quad \times 370$. 
that there is little or no death of androgenetic embryos in spite of their development in cytoplasm irradiated with doses from six to fifteen times that lethal for the egg nucleus.

A study of Plate I will illustrate some points of cytology. It should be recalled here that Habrobracon chromosomes are extremely small. This will explain why they are not always represented exactly as to form and number $(n=10)$. In Plate I, Figure 1, is shown a typical "tear-drop" pronucleus. Polar nuclei are degenerating and suggest by their condition that the egg pronucleus is considerably retarded. Chromatin at the outer end of, as well as within, the egg pronucleus, is attached to bridges. This egg was not fertilized. Figures 3 and 4 show what can happen to such a tear-drop as that just described. The spindle is that of the first cleavage, and bridges with chromatin thickenings can be seen, still attached to chromosomes on the spindle. This is the only egg studied in which the chromatin connections could not be followed continuously from polar nuclei to egg pronucleus. What happens to a tear-drop pronucleus in the majority of cases when an X-rayed egg is fertilized after treatment, is shown in Figure 5. It unites with the normal male pronucleus and, in doing so, ultimately kills the embryo because of upset in chromosome balance due to chromatin loss.

Figure 2 strongly suggests an incipient androgenetic male. The egg pronucleus is so retarded and the male pronucleus so advanced that subsequent syngamy seems highly improbable.

Figures 6,7 , and 8 represent the only eggs found in which androgenetic development had begun. The isolation of the egg pronucleus from cleavage figures, with no evidence of any chromatin connection or remains between them and the normal appearance of the cleavage chromosomes, are to be noted. Figure 8 is especially convincing.

These three eggs have one thing in common which is rare in control eggs and not the rule in X-rayed ones: cleavage is taking place more posteriorly than one would expect. This suggests that some cytoplasmic factor, perhaps greater fluidity of the cytoplasm, may alter action of the sperm pronucleus so that it has moved "beyond the reach" of the impeded egg pronucleus.

\section{Discussion}

It is definitely established that androgenetic development (haploid) occurs in Chaetopterus and in Habrobracon after irradiation in metaphase I. Concerning Bombyx, Kawaguchi (1928) states, "Die Kerne in den Ovarialeiern der Schmetterlinge nach ihrem Ausschlüpfen aus der Puppe stehen fast immer im Stadium der Metaphase der ersten Reifteilung." This indicates that in Bombyx also treatment was given in metaphase I, since adult females were irradiated and then mated to untreated males.

That there is some special cytological response of tetrads to irradiation which causes chromatin bridges to be formed in division II, is apparent in both Chaetopterus and Habrobracon. The author (1945b) has discussed this in some detail but has been prevented from checking the theory completely by the small size of Habrobracon chromosomes. Chaetopterus chromosomes are relatively large and distinctive in character and should be analyzed in detail from this viewpoint. Packard describes chromatin bridges (dicentrics) in cleavage in eggs irradiated with doses low enough 
to permit the egg pronucleus to function in syngamy, a fact consistent with the conditions found in Habrobracon.

No cytological study of Bombyx eggs after treatment has been made. Hasimoto's conclusion, derived from genetic data, that androgenetic males (diploid) arise from the union of two sperm pronuclei, is not inconsistent with the suggestion that, in this form also, chromatin bridges retard the egg pronucleus.

That some viscosity change may be involved in Habrobracon androgenesis as well as chromatin attachment of the egg pronucleus to the polar nucleus, has been mentioned above. Hasimoto and Astaurow obtained androgenetic males in Bombyx by thermo-activation alone during meiotic divisions and after fertilization, and this may be evidence for viscosity change and movement of sperm pronuclei from their usual position. However, in Chaetopterus the sperm chromosomes remain in their normal position, close to those of the egg, yet syngamy does not occur.

A comparison of other factors in the two insect genera shows further similarities. In both, the percentage of eggs developing into androgenetic adults is low-1.57 per cent in Habrobracon; never higher than 0.273 per cent in Bombyx (Astaurow, 1937). In the former, $54,000 \mathrm{r}$ is the highest dose at which androgenetic males were obtained; in the latter, 27,000 r was the highest dose tested, and they were produced after this treatment. In the Chaetopterus study, treatments were measured in minutes of exposure to radium bromide. After 50 minutes' exposure, about 70 per cent of treated eggs underwent haploid cleavage. At longer treatments the percentage dropped, until prolonged exposure stopped cleavage altogether.

In Chaetopterus, incidence of androgenesis but not adult survival; in Bombyx, adult survival but not incidence; and in Habrobracon, both incidence and adult survival, have been determined.

\section{SUMMARY}

1. 1.57 per cent of Habrobracon eggs X-rayed in first meiotic metaphase $(14,420$ $\mathrm{r}-28,840 \mathrm{r}$ ) and laid by treated females mated to untreated males develop into androgenetic males. These will develop after any dose up to $54,000 \mathrm{r}$ although lethal dose for the egg chromosomes in this stage is $2400 \mathrm{r}$. Cytological study of 294 such eggs $(14,420 \mathrm{r}-36,050 \mathrm{r})$ shows that three were undergoing androgenetic cleavage while three others were possibly preparing for it. A maximum of six, or 2.04 per cent, does not differ significantly from androgenetic survivors, and it must be concluded that androgenetic embryos at doses used are a; viable as embryos developing in untreated eggs.

2. Chromatin bridges which appear in meiotic division II after treatment in first meiotic metaphase retard and distort the egg pronucleus, occasionally to such a degree that the sperm pronucleus-cleaves and develops into a normal fertile haploid male with paternal traits only. The almost complete absence of these bridges after treatment in first meiotic prophase will explain the failure of androgenetic males to develop in these eggs.

\section{LITERATURE CITED}

Astaurow, B. L., 1937. Versuche über Experimentelle Androgenese und Gynogenese beim Seidenspinner (Bombyx mori L.). Biologicheskij Zhurnal, 6: 3-50.

Darlington, C. D., 1937. Recent advances in cytology. Philadelphia, Blakiston. 
Hasimoto, Haruo, 1934. Formation of an individual by the union of two sperm nuclei in the silkworm. Bull. Imper. Sericult. Exp. Sta., 8: 463-464.

Kawaguchi, E., 1928. Zytologische Untersuchungen am Seidenspinner und seinen Verwandten. Z. f. Zellforsch. u. mikr. Anatomie, 4: 519-552.

Packard, Charles, 1918. The effect of radium radiations on the development of Chaetopterus. Biol. Bull., 35 : 50-71.

Sharpe, Lester W., 1934. Introduction to cytology. New York, McGraw-Hill.

Speicher, B. R., 1936. Oogenesis, fertilization and early cleavage in Habrobracon. Jour. Morph., 59: 401-421.

Whiting, Anna R., 1938. Sensitivity to X-rays of stages in oogenesis of Habrobracon. Rec. Genetics Soc. Am., $7: 89$.

Whiting, Anna R., 1941. X-ray sensitivity of first meiotic prophase and metaphase in Habrobracon eggs. Rec. Genetics Soc. Am., 10: 174.

Whiting, Anna R., 1945a. Effects of X-rays on hatchability and on chromosomes of Habrobracon eggs treated in first meiotic prophase and metaphase. Amer. Naturalist, 79 : 193-227.

Whiting, Anna R., 1945b. Dominant lethality and correlated chromosome effects in Habrobracon eggs X-rayed in diplotene and in late metaphase I. Biol. Bull., 89: 61-71.

Whiting, Anna R., 1946a. Motherless males from irradiated eggs. Sci., 103: 219-220.

Whiting, Anna R., 1946b. Androgenetic males from eggs X-rayed with dose many times lethal. Rec. Am. Soc. Zool., 96: 11.

Wilson, E. B., 1925. The cell in development and heredity. New York, Macmillan. 


\section{$2 \mathrm{BHL}$ Biodiversity Heritage Library}

Whiting, Anna R. 1948. "INCIDENCE AND ORIGIN QF ANDROGENETIC MALES IN X-RAYED HABROBRACON EGGS." The Biological bulletin 95, 354-360. https://doi.org/10.2307/1538190.

View This Item Online: https://www.biodiversitylibrary.org/item/17418

DOI: https://doi.org/10.2307/1538190

Permalink: https://www.biodiversitylibrary.org/partpdf/3771

\section{Holding Institution}

MBLWHOI Library

\section{Sponsored by}

MBLWHOI Library

\section{Copyright \& Reuse}

Copyright Status: In copyright. Digitized with the permission of the rights holder.

License: http://creativecommons.org/licenses/by-nc-sa/3.0/

Rights: https://biodiversitylibrary.org/permissions

This document was created from content at the Biodiversity Heritage Library, the world's largest open access digital library for biodiversity literature and archives. Visit BHL at https://www.biodiversitylibrary.org. 